\title{
O Xamanismo da Psicologia
}

\section{The Shamanism of the Psychology}

\section{Alexandre Franca Barreto}

Universidade Federal do Vale do São Francisco (Petrolina). Juazeiro, Brasil. alefrancabarreto@gmail.com

RESUMO | INTRODUÇÃO: O Xamanismo está presente na humanidade desde o período Paleolítico, muitos recursos do campo psicológico dialogam implícita ou explicitamente com esta tradição: a hipnose, o efeito placebo, a interpretação dos sonhos, técnicas meditativas de visualização, relaxamento e dramatização, a catarse e o manejo de sentido e simbolismo nas doenças e eventos da vida são exemplos. OBJETIVO: Reconhecer a presença do xamanismo e seus saberes afins à psicologia, visibilizando suas contribuições na atualidade. MÉTODO: Trata-se de um estudo teórico com base uma revisão bibliográfica narrativa. RESULTADOS: Procuramos reconhecer o xamanismo da psicologia partindo de uma crítica descolonial da história da psicologia e do xamanismo. Em seguida, destacamos algumas traduções epistemológicas que ajudam no reconhecimento do xamanismo na atualidade: a ideia de especialidade biológica; a noção de tecnologias do sagrado; bem como a incorporação da meditação e dos psicodélicos como inovação "psi". CONCLUSÃO: Apresentamos três importantes considerações: a validade do xamanismo pela ciência não deve ser baliza de seu mérito; a psicologia deve construir uma reflexividade ética para não atuar como colonizadora do xamanismo e, por fim, reconhecer o xamanismo da psicologia permite reconhecer o próprio campo no qual é agente.

PALAVRAS-CHAVE: Xamanismo. Colonialismo. História. Prática Psicológica.

\begin{abstract}
INTRODUCTION: Shamanism has been present in humanity since the Paleolithic period. Many resources in the psychological field come from this tradition: hypnosis, the placebo effect, the interpretation of dreams, meditative techniques of visualization, relaxation and dramatization, catharsis, and the management of meaning and symbolism in diseases and life events are examples. OBJECTIVE: Recognize the presence of shamanism and its knowledge related to psychology, making its contributions and contributions visible today. METHOD: This is a theoretical study based on a narrative bibliographic review. RESULTS: We tried to recognize the shamanism of psychology based on a decolonial critique of the history of psychology and shamanism. Then, we highlight some epistemological translations that do not recognize shamanism today: the idea of biological specialty, a notion of technologies of the sacred, as well as the incorporation of meditation and psychedelics as a "psi" innovation. CONCLUSION: We present three important considerations: the validity of shamanism by science should not be a mark of merit; psychology must build ethical reflexivity in order not to act as a colonizer of shamanism; and, finally, recognizing the shamanism of psychology allows us to recognize the very field in which it is an agent.
\end{abstract}

KEYWORDS: Shamanism. Colonialism. History. Practice Psychological. 
Somos ponta de rama - Honrando milênios de histórias de cuidado

Os brancos se dizem inteligentes. Não o somos menos. Nossos pensamentos se expandem em todas as direções e nossas palavras são antigas e muitas. Elas vêm de nossos antepassados. Porém, não precisamos, como os brancos, de pele de imagens para impedir de fugir de nossa mente. Não temos que desenhá-las, como eles os fazem com as suas. Nem por isso elas irão desaparecer, ficam gravadas dentro de nós. Por isso nossa memória é longa e forte. (Kopenawa \& Albert, 2013/2015, p. 75)

Inicio este texto com a citação do xamã yanomami Davi Kopenawa ao afirmar a consciência de seu saber ancestral na tradição oral de seu povo. Ouvi do Cacique Neguinho - liderança indígena Truká no território localizado em uma ilha fluvial no Rio São Francisco no Município de Cabrobó - o seguinte dizer: "somos ponta de rama". Quando eu estava participando de um encontro com professoras/es indígenas do território Truká, ele proferiu uma fala lembrando todos/as presentes que eles são "pontas de rama" e se explicou dizendo que as raízes deles são seus ancestrais. Tomando esta metáfora botânica, de forma simples, ele penetra na mesma profundidade abordada por Kopenawa, sua identidade, cultura, terra e os ensinamentos mais profundos que auxiliam nos desafios existenciais dando força e discernimento. De pé, enraizados na vida, honrando suas tradições à medida que reconhecem a história de seu povo, de seus ancestrais, suas lutas, seus modos de sobrevivência e toda a sabedoria acumulada ao longo de séculos preservada pela oralidade, mesmo diante de tantas violências sociais e culturais que sofreram.

Este ensinamento, dito para seu povo, ecoou dentro de mim, reconheci a sabedoria naquela fala. Até então entendia a importância do enraizamento (grounding) por uma influência da psicologia somática na Bioenergética de Lowen (1994/2017). O grounding, para o autor, refere-se a uma postura corporal e existencial de centramento, consciência corporal e autossustentação em nível biográfico. A perspectiva de enraizamento indígena Truká me fez rever a importância deste conceito, a partir de uma conexão com nossos antepassados e a ancestralidade, expandindo para além de uma história pessoal e dimensão biográfica, um corpo-árvore.
Do meu lugar acadêmico, situado na psicologia e em fronteiras com a saúde e humanidades, fui evocado com estes dizeres a pensar, o (des)enraizamento nos tempos de hoje. Indagações sobre a importância de honrar e reconhecer o valor dos saberes indígenas no campo da psicologia sob um risco de desenraizamento do conhecimento. Aqui uma questão parece extremamente relevante: refere-se ao risco do caráter monolítico do cânone epistemológico e o exclusivismo epistemológico da psicologia, que ceifa saberes sobre seu "objeto", instituídos sob outras bases de conhecimento (Santos, 2008a). Este aspecto é profundamente problematizado no debate descolonialista, que reconhece no genocídio de povos indígenas em seu território um polo de sustentação no epistemicídio de seus saberes protagonizado nas universidades e ciências (Grosfoguel, 2016).

Abordar este aspecto, sem dar conta de sua totalidade, mas destacando a importância deste como ponto de partida, permite olhar para o xamanismo na psicologia como um exercício de reconhecimento de sua história (não apenas científica moderna) fronteiriça. Aqui, temos não apenas uma validade epistêmica, mas ética e política da importância dos saberes tradicionais na própria estruturação de uma psicologia brasileira e latino-americana que procure uma ecologia de saberes (Santos, 2008a). Honrando nossos antepassados que coabitam este território e o acúmulo de sabedoria construída, por um lado, rompemos uma concepção de "conhecimento-regulação", no qual "a ignorância é concebida como caos e o conhecimento como ordem" (Santos, 2008a, p. 155) e gera riscos de um desenraizamento de nossas teorias e práticas psicológicas. Por outro lado, passamos então a um olhar de "conhecimento-emancipação", no qual "a ignorância é concebida como colonialismo e o saber como solidariedade" (Santos, 2008a, p. 155).

A psicologia, ao se debruçar apenas em uma breve história científica e moderna, pode negligenciar, desqualificar e cindir um importante acumulo de conhecimento e práticas que foram fundamentais para nós humanos compreendermos o universo psíquico, bem como formular teorias objetivas e práticas sobre o funcionamento do psiquismo, da subjetividade e do corpo e da coletividade. 
Reconhecer o xamanismo como origem arcaica da Psicologia não significa apontar conhecimentos rudimentares de um período e raça inferior ao atual, mas destacar na história da humanidade, desde o período paleolítico (segundo a história ocidental) até os dias atuais, a importante presença do xamanismo e seus saberes nas fronteiras da psicologia (Rock \& Kripnner, 2011), assim como dar visibilidade a diálogos e contribuições do xamanismo com o devido respeito e honra a esta tradição ancestral.

Defendo aqui a importância de dar um lugar legítimo e de honra a este conhecimento ancestral e profundo da humanidade desenvolvido ao longo de milênios, nos quais podemos observar diferentes recursos, perspectivas e técnicas de acesso e manejo do objeto da psicologia seja ele a subjetividade, o comportamento ou a mente. Malradi e Martins (2016) fazem uma lista de contribuições dos saberes xamânicos à psicologia, apoiando-se em diversos estudos, e destacam: o uso da hipnose, do efeito placebo, a interpretação dos sonhos, técnicas meditativas de visualização, relaxamento e dramatização, além do uso da catarse e o manejo de sentido e simbolismo nas doenças e eventos da vida. Vale destacar, por fim, a habilidade das tradições xamânicas em atuar conscientemente em diferentes estados ou níveis de consciência diversos do estado de vigília ou ordinário (Krippner, 2007).

Neste trabalho, há uma preocupação acadêmica com o ensino e a formação em psicologia. Em meu período de graduação ao final dos anos 90 e inicio do século XXI, vivíamos, na psicologia brasileira, uma revisão de sua história a partir de importantes problematizações sobre a postura ideológica de nossa ciência e profissão, bem como um importante desafio de sistematizar a história da psicologia protagonizada em solo nacional. Houve um esforço para incluir outras narrativas importantes acerca da psicologia e seus movimentos internos, tendo como debate ético o compromisso social da psicologia, observando como o nosso campo contribuiu significativamente no reforço de estigmas sociais e desigualdades. Alimentou-se a ideia de "desvio" do sujeito, deslocando problemas complexos de vínculo, laço social e violências estruturais para a culpabilização de determinadas pessoas e grupos (Jacó-Vilela et al., 2006; Bock et al., 2018). Me parece bastante salutar este avanço na reedição crítica da história da psicologia enquanto ciência e profissão.
Neste momento que entramos na terceira década do século XXI, contudo, atravessamos uma situação social catastrófica, não apenas embalada pelo contexto de uma pandemia global com milhares de mortes, mas também por uma onda de obscurantismo, permeada por narrativas negacionistas e fascistas, na qual as ciências humanas (incluindo a psicologia) estão sendo desqualificadas e desvitalizadas, não apenas por uma injustiça cognitiva, mas intencionalmente "tem gerado estruturas e instituições que produzem o racismo/sexismo epistêmico, desqualificando outros conhecimentos e outras vozes críticas frente aos projetos imperiais/coloniais/patriarcais que regem o sistema-mundo" (Grosfoguel, 2016, p. 25). Enquanto isso, algumas vertentes da psicologia se esforçam profundamente para se dissociar deste laço com as humanidades afeitos a uma ligação exclusiva com as ciências biológicas e da vida.

Neste contexto, observo que os livros de história da psicologia, mesmo as obras citadas anteriormente que revisam a história da psicologia brasileira, não reconhecem as raízes ancestrais da psicologia no xamanismo. A história da psicologia geralmente é contada a partir de suas raízes gregas seguindo os séculos posteriores quase exclusivamente com base no conhecimento produzido em solo europeu e americano demarcando uma narrativa reconhecidamente colonialista (Santos, 2008a; Grosfoguel, 2016). Nestas últimas décadas, aumenta-se o volume de publicações sobre história moderna da psicologia. Estas obras apresentam inúmeros méritos, e à medida que nossa ciência se desloca no tempo, mais sua história cresce e tais recortes são fundamentais para debruçar-se sobre a riqueza dos acontecimentos (Schultz \& Schultz, 2002; Hothersall, 2019). Contudo, me parece necessário observar os silenciamentos nestas obras, ao analisarmos os protagonistas desta história da psicologia e o território no qual todo enredo acontece, nos deparamos com a visão colonialista universalizante de uma episteme euro-norte americana. A negação, dissociação ou desconhecimento se fazem através de um silenciamento mais ou menos intencional de diversos outros saberes.

Não é incomum observar docentes e pesquisadores que promovem a divulgação cientifica, e também estudantes de psicologia em formação utilizarem narrativas de negação e desqualificação ao falar de xamanismo ou xamãs. Atribui-se à "magia” um pensamento infantilizado, fala-se de xamãs como ingênuos 
(reduzindo sua capacidade intelectual) ou como charlatões (desqualificando a dimensão ética de suas práticas), imprime-se um discurso de violência perante o diferente sobre a égide de uma narrativa monolítica da ciência psicológica, arrogando-se do poder da ciência para simplificar questões extremamente complexas sobre verdade, política, conhecimento, visão de mundo e cultura.

Estes fatos atendem a padrões de controle, hierarquização e classificação que afeta todas as dimensões da existência social, e que tem no conceito de raça seu eixo estruturante. Quijano (2005) conceituou este fenômeno como colonialidade do poder. Mesmo com o termino do colonialismo, a colonialidade "se mantém arraigado nos esquemas culturais e de pensamento dominantes, legitimando e naturalizando as posições assimétricas em que formas de trabalho, populações, subjetividades, conhecimentos e territórios, são localizadas no mundo contemporâneo" (Porto-Gonçalves \& Quental, 2012, p. 8).

Por isto, pretendo trazer, neste artigo, alguns importantes apontamentos que ajudem a compreender o lugar de honra e a grande contribuição que o xamanismo tem para psicologia, em sua história e atualidade. Considerando a contribuição do debate descolonialistas, recontar um pouco da história, contar de um outro modo, ou ainda, evidenciar os saberes silenciados ou estratificados, permite recentrar o modo de pensar e fazer ciência e produzir conhecimento - sob estes aspectos todo o movimento do final do século passado da psicologia brasileira e latino americana como pontuado anteriormente formam um terreno fértil para o avanço deste debate. O desenvolvimento dos estudos nos campos da antropologia, psiquiatria, ciências do comportamento, cognição e neurobiologia na interface dos fenômenos psicológicos e xamanismo, permitem também um olhar de tradução mais profunda do que apenas rotulá-lo como um pensamento primitivo e inferior ao científico.

\section{Da magia à técnica - uma mudança de tradução do xamanismo}

A ideia de tradução parte de um princípio de douta ignorância, no qual toma como desafio a comparação de saberes marcados por diferença epistemológica, intercultural. Santos (2008b) comenta:
A existência da diferença epistemológica faz com que a comparação tenha de ser feita através de procedimentos de busca de proporção e correspondência que, no conjunto, constituem o trabalho de tradução. Como referi, para que estes procedimentos actuem é necessário que eles sejam levados a cabo por todos os saberes que compõem um dado círculo de ecologia de saberes. Na acepção que aqui Ihe dou, a tradução é tradução recíproca. Através dela, a diferença epistemológica, ao ser assumida por todos os saberes em presença, torna-se uma diferença tendencialmente igual. Os procedimentos de proporção

e correspondência são procedimentos indirectos que permitem aproximações sempre precárias ao desconhecido a partir do conhecido, ao estranho a partir do familiar, ao alheio a partir do próprio. Entre eles, menciono sinais, símbolos, conjecturas, enigmas,

pistas, perguntas, paradoxos, ambiguidades, etc. $O$ uso recíproco destes procedimentos, longe de eliminar

a incompletude de cada saber, aumenta-a. A douta ignorância consiste precisamente em levar ao máximo a consciência dessa incompletude (p. 29).

Tomando como base este exercício de tradução, reconhecendo sua precariedade e complexidade é que vamos nos debruçar sobre o xamanismo. Ao se falar de xamã ou xamanismo, nos referimos a um conceito antropológico construído a partir de dados sobre importantes membros do povo Tugo da Sibéria (yamã) que cumpriam uma função social específica. $O$ aspecto fundamental do Xamã, nas palavras de Eliade (2002), é a experiência extática, um "mestre do extasê", e o xamanismo é entendido como técnicas de êxtase por este autor (p. 15).

Do ponto de vista histórico, é possível afirmar que os xamãs foram os primeiros humanos, ainda no período paleolítico, a cuidar e curar outros humanos em seus processos de adoecimento físico, mental e espiritual, pois dentro de sua concepção não havia separatividade destes processos (Eliade, 2002; AldhouseGreen \& Aldhouse-Green, 2005).

Rock e Kripnner (2011) afirmam que: "One could make the claim that shamans appear to have been humankind's first psychotherapists, first physicians, first magicians, first performing artists, first storytellers, and first weather forecasters" (p. 184)."

Alguns estudos arqueológicos e transculturais apontam a existência de xamãs desde 30 mil anos A.C. (Aldhouse-Green \& Aldhouse-Green, 2005; Winkelman, 2010), e sua presença ocupa uma 
importante função social de prestígio e legitimidade, confirmada pela comunidade assistida por eles.

É valido destacar aspectos culturais diversos no xamanismo, bem como os estudos contemporâneos que mapeiam diferentes estados de consciência que procuram relativizar o conceito único apontado por Eliade (2002), do xamã como um "mestre do êxtase". Deste modo, Rock \& Kripnner (2011) sugerem um conceito operacional para compreender os xamãs de uma perspectiva psicológica contemporânea: são praticantes espirituais sancionados pela comunidade que deliberadamente direcionam sua atenção na tentativa de acessar informações que normalmente são inacessíveis os membros de seu grupo social. Assim, os xamãs adotam uma postura ativa de modular seus estados de atenção (através de técnicas específicas) em benefício comunitário.

Contudo, precisamos compreender que, para aceitar este conceito, muitas compreensões estereotipadas acerca dos xamãs e suas práticas foram sendo revisitadas por pesquisadores ao longo do último século. Na modernidade, as primeiras impressões acerca dos xamãs a partir de dados antropológicos, psicológicos e psiquiátricos foram significativamente depreciativas. Os xamãs eram vistos como pessoas com transtornos mentais, com saúde física frágil, doentes dos nervos, epilético, taciturno, histérico (Eliade, 2002; Rock \& Krippner, 2011), dentre outros adjetivos que desqualificam a importância social que o mesmo ocupava em suas comunidades, criando um estereótipo negativo de invalidação do valor dos primeiros curadores da humanidade.

As histórias de vida de xamãs, geralmente acometidos por doenças físicas, transtornos de sono e experiências de privação social parecem ter marcado profundamente este olhar. Porém, um aspecto não observado inicialmente é que estas narrativas fazem parte das crises existenciais que marcam o ingresso do xamã em sua jornada de formação para ocupar esta função. Uma certa crise existencial parece marcar a história dos xamãs em diversas tradições ao redor do globo. Eliade (2002) nos ajuda a compreender que este fato é o despertar da jornada xamânica que faz estes neófitos em crise receberem todo o processo de iniciação e formação de xamãs antigos para que possam tornar-se "curadores que curaram a si mesmos".
O percurso formativo destes xamãs envolve assim um aprendizado em profundidade do sofrimento vivido em sua jornada e, ao serem adequadamente orientados e instruídos pelos mais experientes, se formam através de imersões em experiências extáticas, ritos iniciáticos e uma série de procedimentos mais ou menos rigorosos que envolvem dieta, reclusão, vestimentas, o conhecimento e uso de plantas e elementos da natureza. Este processo que pode ser mais ou menos duradouro, e confere a eles um lugar existencial e a autoridade social de xamã, na medida em que superam as crises de sua fase neófita e passam a auxiliar não apenas a si em suas curas, mas também a outras pessoas da comunidade.

À medida que estudos com maior rigor no exercício de tradução no encontro com as diferenças epistemológicas foram acontecendo, os olhares desqualificadores passaram a ser questionados introduzindo outras facetas para a personalidade do xamã e de sua importância social. Em antagonismo às narrativas anteriores, observou-se que xamãs detinham uma vitalidade física surpreendente, significativa habilidade cognitiva e intelectual com vasto conhecimento sobre a sua cultura e a natureza circundante, apresentavam uma sensibilidade e capacidade de concentração impressionante, suportavam exercícios extenuantes e conseguiam controlar seus movimentos extáticos (Eliade, 2002; Winkelman, 2010).

A formação dos xamãs se mostra profundamente rigorosa e exigente. Moebus (2017) destaca a necessidade de fazermos um deslocamento do modelo convencional de formação médica centrado no pensamento racional lógico-formal, empirista, tecnicista e especialista para compreender este outro "modo" formativo. $O$ autor refere que a formação de um pajé, a depender da tradição, inicia na infância, para ocupar esta função em um processo de aprendizagem profundamente duradouro.

Na obra "A queda do céu", Kopenawa e Albert (2015) retratam a árdua formação xamânica yanomami de Davi Kopenawa, que teve início na infância, a partir das orientações recebidas por xamãs experientes acerca de seus sonhos perturbadores. Anos convivendo com os sonhos e sendo orientado, na adolescência foi introduzido ao pó de yãkoana e aprofundou sua compreensão acerca do mundo dos sonhos e dos mortos. O mesmo fala que seus aprendizados não são através de livros, mas de ver por si mesmo. 
“(...) no silêncio da floresta, nós, xamãs, bebemos o pó das árvores yãkoana hi, que é o alimento dos xapiri. Estes então levam nossa imagem para o tempo do sonho. Por isto somos capazes de ouvir cantos e comtemplar suas danças de apresentação enquanto dormimos. Essa é a nossa escola, onde aprendemos as coisas de verdade." (Kopenawa \& Albert, 2015, p.76)

Apesar de um olhar científico inicial traçar um rótulo de "magia" ou "charlatanismo" desqualificante para o xamã, o que se observa mais cuidadosamente é que há um amplo processo de técnicas e procedimentos sistemáticos que conferem esta função social. Outro fator importante é que nossa ciência psicológica, durante décadas, convencionou rotular como patológico estados de consciência diferentes da vigília, interpretando que a experiência de outros estados conscienciais eram algum tipo de distúrbio do funcionamento normal (Grof, 2015).

Sobre estes aspectos, a obra de Jung (1951/2000) ajudou a interpretar com maior complexidade os fenômenos da consciência, em especial ao introduzir o inconsciente coletivo, no qual a adota o conceito de arquétipo para se referir a expressões de base instintivas universais que fazem parte da consciência humana. O psiquiatra Grof (1985/1987), que sofreu influências de Jung, contribuiu, ainda no início da segunda metade do século passado, para a psicologia revisar sua compreensão sobre a complexidade da consciência em diferentes estados atencionais, a manifestação destes estados, e os recursos/técnicas de acesso ao mesmo.

Grof $(1985 / 1987,2015)$, ao se apoiar em alguns estudos antropológicos, adota uma expressão "tecnologias do sagrado" para se reportar ao acumulo de conhecimento técnico dos povos tradicionais em como modular a consciência para estados não ordinários, retrata, deste modo, uma compreensão de que diversas culturas valem-se de técnicas específicas conduzidas por xamãs para intervir em níveis de consciência distintos, operar insights, promover a cura, aliviar um sofrimento e fornecer uma conexão entre o mundo comum e os reinos supostamente visitados pelo xamã - que remetem a um domínio de ligação com ancestrais, demônios e divindades que tem importante valor simbólico para as pessoas que o buscam.
Estas tecnologias envolvem uma série de recursos complexos e específicos que podem dispor da estruturação de rituais que atuam de modo multissensorial estimulando olfato, tato, paladar, visão e audição (Grof, 2015; Rock \& Krippner, 2011). A preparação do ambiente, cantos e uso de palavras, o uso de tambor e/ou outros instrumentos musicais, dietas, substâncias psicoativas, toques corporais, privação de sono, instrumentos simbólicos-ritualísticos, incensos e ervas aromáticas, dentre outros recursos podem ser adotados.

Rock e Krippner (2011) sugerem uma epistemologia xamânica formada com base nas necessidades humanas ancestrais:

"Epistemology is concerned with the nature, characteristics, and processes of knowledge, and in this chapter we are suggesting that shamanic epistemology drew upon perceptual, cognitive, affective, and somatic ways of knowing that assisted early humans to find their way through an often unpredictable, sometimes hostile, series of environmental challenges. Not only did early humans have to become aware of potentially dangerous environmental objects and activities, they needed to have explanatory stories (enacted as mythic rituals) at their disposal to navigate through the contingencies of daily encounters and challenges. The acute perceptual abilities of shamans, in combination with their intuition and imagination, attempted to meet their societies' needs." (p. 42)

Procurando compreender a natureza, as características e os processos de conhecimento relacionado aos cuidados tradicionais indígenas Yawanawás, o psiquiatra Moebus (2017) aponta para uma "racionalidade' intuitiva, relacional e integral, tanto no modo como se acessa o conhecimento como se pratica e compartilha o cuidado e os saberes.

O processo de cuidado envolve uma "busca intuitiva, e não racional, é preciso intuir. O que se busca é perceber sensivelmente o que se passa, e não a construção de uma explicação ou compreensão racional, causal" (Moebus, 2017, p. 35). A dimensão relacional está associada à ideia de que "saúde e a doença, o tratamento e a cura estão ligados ao conjunto de relações que compõe a pessoa. Nunca é um indivíduo, mas constituído pelas relações familiares, afetivas e amorosas" (Moebus, 2017, p. 36). E o aspecto integral remonta a toda a visão do fenômeno de forma integrada sem tratar de forma fragmentada o problema. 
O multiperspectivismo do antropólogo brasileiro Castro (2017) auxilia a compreender a visão de mundo xamânica na qual a ideia de humanidade se refere a um espectro muito mais amplo do que a "espécie", há um ideal moral do qual "o universo é povoado de intencionalidades extra-humanas dotadas de perspectivas próprias" (p. 309). O autor segue afirmando que:

"O xamanismo amazônico pode ser definido como a habilidade manifesta por certos indivíduos de cruzar deliberadamente as barreiras corporais e adotar a perspectiva de subjetividades aloespecíficas, de modo a administrar as relações entre estas e os humanos. Vendo os seres não humanos como estes se veem (como humanos), os xamãs são capazes de assumir o papel de interlocutores ativos no diálogo transespecífico; sobretudo, eles são capazes de voltar para contar a história, algo que os leigos dificilmente podem fazer.... Se o "multiculturalismo" ocidental é o relativismo como política pública, o perspectivismo xamânico ameríndio é o multiculturalismo como política cósmica." (Castro, 2017, p. 310)

Vamos agora nos dedicar a refletir um pouco mais sobre esta dimensão aloespecífica sobre a qual o autor comenta, que procuramos compreender aqui como uma propriedade da consciência. Estudos em diálogos com o campo da psicologia, cognição e neurociência nos auxiliam a compreender esta prática de modo atualizado e de seus impactos na vida humana, e na herança destes xamãs para psicologia.

\section{A especialidade xamânica: um modo interpretativo de reconhecimento da razão ocidental sobre a tradição}

Alguns estudos procuram demonstrar que o xamanismo se desenvolveu como uma especialização social e trouxe contribuições para a evolução da consciência humana. Uma vez que praticamente não houveram modificações genéticas nos últimos 90 mil anos no Homo Sapiens sapiens, a hipótese que Rock e Krippner (2011) defendem é que foram os fatores ambientais e socioculturais que determinaram esta evolução mental. Neste sentido, o xamanismo ocupa uma raiz sociocultural que incide sobre as condições biológicas da humanidade, estimulando o desenvolvimento de propriedades neurognósticas.
O termo neurognóstico refere-se ao processo de especialização dos xamãs de apropriação e conhecimento de funções cognitivas e neurológicas inatas. Tais propriedades neurognósticas envolvem redes neurais que fornecem substratos biológicos para forma de conhecimento xamânico (Rock \& Krippner, 2011).

Esta especialização é interpretada por Winkelman (2010) como uma derivação biológica relacionada a adaptações culturais. A cognição, percepção e afeto são geradas com base neste potencial neurognóstico do sistema nervoso de nosso organismo.

Baseados em estudos de história natural e evolutivos, Rock e Krippner (2011) sugerem que o desenvolvimento da linguagem para expressão e comunicação, através da arte rupestre e da criação de mitos e rituais xamânicos, foram um esforço evolucionário para garantir a sobrevivência por um lado, e, por outro lado, criar espetáculos impressionantes de atuação que geravam comoção, solidariedade e envolvimento comunitário. Sob estes aspectos, a fabricação da imagem e símbolos operavam dentro de propriedades neurognósticas e predisposições genéticas que contribuíram para a evolução da consciência, além de especializações perceptivas, no que se refere aos sonhos, intuições e observações agudas do mundo natural e social.

Winkelman (2010) aponta as ritualísticas xamâmicas como as primeiras práticas institucionalizadas que proporcionam ao mesmo tempo uma mudança no padrão de consciência e modificações no vínculo comunitário, proporcionando o aumento da solidariedade e o aperfeiçoamento de funções neurognósticas.

Ao tratar do ritual xamânico, Winkelman $(2002,2010)$ interpreta o desempenho do xamã como uma atividade que reflete modos de consciência com base biológica, destaca que há uma substituição do estado habitual de vigília por meio de condutas e padrões específicos que operam uma sincronização e coerência inter-hemisférica, integrando córtex límbico e descargas integrais que sintetizam a cognição e afetam o comportamento. 
Mandell (1980) aponta uma variedade de procedimentos, agentes e tecnologias (um exemplo, é uso de tambores) que estão disponíveis no ritual xamânico para evocar descargas de ondas lentas do sistema límbico que sincronizam o córtex frontal.

A fantasia e a imaginação presentes no extenso simbolimo dos rituais podem facilitar o uso destes recursos como um traço de especialização (Wilson \& Barber, 1983) e contribuiem para o desenvolvimento de uma percepção aguda de seu ambiente (Berman, 2000).

Todas essas características apontandas podem estar relacionadas à evolução do cérebro humano, a saber, o desenvolvimento de subsistemas especializados que são ativados durante as mudanças na consciência. A evolução cortical pode ser avaliado não apenas através da sofisticação cada vez maior de circuitos corticais especializados, mas uma flexibilidade e ampliação representacional (Winkelman, 2010).

Neste sentido, modos interpretativos recorrentes de xamãs em suas práticas envolvem: a compreensão de fuga e resgate da alma; busca de espíritos guardiões; a comunicação com ancestrais mortos, animais e plantas, e; experiências de morte e renascimento. Estas experiências xamânicas são assimilados como estados alterados de consciência diferentes do estado de vigília.

Krippner (2007), ao situar estudos relacionados ao campo dos estados alterados de consciência (EAC), aponta que a observação em diversas culturas e a recorrência destes fenômenos conclui que a capacidade de experienciar EACs é uma capacidade psicobiológica básica de todos os seres humanos.

Winkelman concorda, sugerindo que os dados psiconeurológicos indicam que as tradições xamânicas institucionalizaram procedimentos para superar a fragmentação natural da consciência ao sincronizar a cognição humana pela indução de processos cerebrais integrativos (Winkelman, 2010).

Contudo, Krippner (2007) e Rock e Krippner (2011) sugerem que, ao invés de se falar em estados alterados de consciência (EAC), dado os diferentes modos culturais como se manifesta o xamanismo e diferenças presentes em relatos subjetivos, assim como a ampla gama de reações neurofisiológicas, seria mais adequado falar de padrões fenomênicos de atenção.
Os sonhos e o "estado alfa" relacionado às ondas cerebrais emitidas durante o estado de sono seriam uma exceção aos modos subjetivos e de variações culturais da experiência xamânica.

Grof, ao optar pelos registros fenomenológicos de experiências incomuns de consciência de seus pacientes sob o efeito de psicodélicos, destaca o potencial heurístico e terapêutico destes estados, difereciando o que considera estados ordinários (relacionado ao estado padrão de vigília) do estado holotrópico - que vai em direção a um estado de totalidade $(1987,2010$, 2015). O autor reconhece nas práticas xamânicas um trabalho multissensorial, que combina estímulos na visão, audição, paladar, olfato, tato, ritmo e imaginação de forma a promover outros estados de atenção e consciência.

Grof (2015) defende, com base em sua experiência clinica, que há neste estado holotrópico de consciência um significativo "potencial curativo, transformador e evolucionário" (p. 37), além de uma "valiosa fonte de dados sobre a psique humana e a natureza da realidade" (p. 37). Deste modo, o autor reconhece a importância dos estados não ordinários de consciência induzidos através de estímulos multissensoriais, tal qual os desenvolvidos por tradições xamânicas. $O$ autor destaca que muitas abordagens psicoterapêuticas contemporâneas procuram desenvolver técnicas e recursos, influenciados de maneira direta ou indireta por este conhecimento do xamanismo e de outras tradições espirituais milenares para superar os estados de consciência ordinários do processo terapêutico centrado em técnicas exclusivamente verbais e análises intelectuais.

Considero que um exemplo notável deste aspecto é a adoção nas últimas décadas da meditação e técnicas de respiração em trabalhos psicoterapêuticos de diversas abordagens psicológicas, sendo cada vez mais parte do arsenal de recursos ofertadas pela psicologia no tratamento de diversos transtornos mentais. Muitas destas técnicas são influenciadas pelo budismo e hinduísmo, que apresentam por sua vez significativas influências de tradições xamânicas (Eliade, 1996).

A introdução da meditação na área da saúde procura se diferenciar de práticas tradicionais por uma narrativa de laicidade e não dogmatismo, e tem sido cada vez mais fundamentada por pesquisas neurocientíficas que procuram validar práticas milenares com 
base em descobertas sobre o impacto delas no sistema nervoso, todo o aparato tecnológico científico que permite mensurar movimentos internos neurofisiológicos e os efeitos destes no estado emocional e na sociabilidade (Goleman \& Davidson, 2017; Singer \& Ricard, 2018).

De modo análogo, o estudo com psicodélicos vem sendo uma outra área de "inovação" na psiquiatria (Pollan, 2018). Schenberg (2018) destaca uma tripla crise da psiquiatria que inside na terapêutica, no diagnóstico e na explicação dos processos de adoecimento. Um importante fator para esta crise refere-se ao grande contraste de modelos explicativos que procuram entender os disturbios mentais como disturbios cerebrais por um lado, e outro lado, inúmeros processos complexos etiológicos que envolvem a formação do sujeito em seus vínculos e formação cultural da psique. Dentre inúmeras críticas à psiquiatria, Gøtzsche (2013/2016) destaca uma visão dominante no campo de substituição do cuidado por medicamentos associado ainda a significativos danos iatrogênicos e limitado potencial terapêutico para diversos quadros de sofrimento (a exemplo de Transtorno do Déficit de Atenção com Hiperatividade - TDAH, Depressão e Ansiedade) que tendem a cronificação.

A redescoberta dos psicodélicos clássicos tem prometido um potencial terapêutico e baixo risco dos mesmos para problemas como depressão, ansiedade, dentre outras problemáticas de saúde mental (Schenberg, 2018). São exemplos deste psicodélicos clássicos a psilocibilina (presente nos cogumelos), dimetiltriptamina (encontrada nos preparos da bebida ayahuasca e jurema) e mescalina (princípio ativo do peyote). Todos estas substancias estão presentes em práticas ancestrais xamânicas de povos originários latino americanos (Miller et al., 2019).

Neste cenário, cabe destacar três vertentes crescentes. O crescente turismo terapêutico por parte de populações de países da América do Norte e Europa, bem como moradores urbanos em busca de tratamentos na região Amazônica - com destaque para o Peru. Observamos também um crescente movimento neoxamânico de incorporação de práticas tradicionais do xamanismo com adaptações culturais e no contexto urbano. Por fim, o crescente interesse no campo da psiquiatria para incorporar e sancionar protocolos terapêuticos que envolvam o uso de psicodélicos (Winkelman, 2002; (Schenberg, 2018).
A institucionalização no campo "psi" do uso de técnicas de respiração, meditação, assim como de psicodélicos, tem sido fortemente fundamentados por estudos neurocientíficos associado a estudos clínicos que procuram explicar o benefício destes recursos a partir do entendimento de mudanças em padrões sinápticos, estimulo a funções específicas do cérebro, bem como narrativas que atestam experiências significativas de melhora em quadros de adoecimento e sintomas indesejáveis (Goleman \& Davidson, 2017; Singer \& Ricard, 2018; Pollan, 2018).

Observamos como os estudos recentes no campo do xamanismo, da psicologia e neurociências que se debruçam sobre temas afins procuram validar os saberes, o conhecimento de xamãs e algumas de suas práticas de formas adaptadas têm sido incorporadas em protocolos de pesquisas clínicas, ou já são adotadas como recursos da prática profissional.

Os argumentados apresentados até aqui sinalizam importantes relações entre o xamanismo e o desenvolvimento de capacidades humanas de atenção, percepção, afetividade e vinculação comunitária.

\section{Desafios no diálogo entre psicologia e xamanismo}

À guisa de considerações finais, gostaria de pontuar três desafios neste diálogo intercultural, atravessando por diferentes realidades e fundamentos epistemológicos:

Tradicionalmente, a validade das práticas xamânicas se dá pelos seus praticantes e os ganhos pessoais e comunitários dos mesmos, e isto deve ser respeitado sob o risco de colonização e epistemicídio (Santos, 2008a; Grosfoguel, 2016). Deste modo, os estudos científicos que procuram fazer traduções do xamanismo para seu universo cultural e epistêmico podem contribuir para diálogos cooperativos, sem, contudo, ser juiz do valor ou demérito de tais práticas. Neste sentido, todo o cuidado é necessário, por parte do campo acadêmico de não adotar, a priori, conceitos explicativos de seu campo para validar ou não tais práticas, e sim, traçar possibilidades dialógicas e traduções que respeitem os diversos saberes. 
Vale relembrar que do ponto de vista da histórica ocidental (Rock \& Krippner, 2011), o xamanismo surge de povos caçadores coletores no Paleolítico, produzindo novas configurações em povos agrícolas no neolítico. Contudo, cada vez mais observa-se a presença de um xamanismo urbano nas sociedades ditas modernas, a expressão neoxamanismo tem sido adotada para explicar tal fenômeno (Fernandes, 2018). Igualmente, a incorporação de recursos e técnicas influenciadas pelo xamanismo na atuação de profissionais da saúde (incluso a psicologia) são fatos que carecem de uma profunda reflexividade ética. Para não correr riscos de a psicologia em seu encontro com o xamanismo colonizar "novos espaços abertos ao conhecimento pelos "velhos modelos" (Santos, 2008a, p. 147).

Por fim, considero que a psicologia, em especial a latino americana, deve reconhecer o "xamanismo da psicologia", dar um importante lugar de honra em sua história a esta tradição milenar que traz importantes contribuições para compreensão do objeto da psicologia em suas múltiplas manifestações: subjetividade, psiquismo, cognição, afetividade, percepção, estados de consciência, relações sociais e comunitárias. Dar este lugar de honra ao xamanismo não apenas significa recontar nossa história na complexidade epistêmica e intercultural, mas também dar passos significativos ao exercício de uma profissão e campo do saber que amplie sua reflexividade ética e política sobre os processos colonizadores dos quais o próprio campo atua como agente.

\section{Conflitos de interesses}

Nenhum conflito financeiro, legal ou político envolvendo terceiros (governo, empresas e fundações privadas, etc.) foi declarado para nenhum aspecto do trabalho submetido (incluindo, mas não se limitando a subvenções e financiamentos, participação em conselho consultivo, desenho de estudo, preparação de manuscrito, análise estatística, etc.).

\section{Referências}

Aldhouse-Green, M., \& Aldhouse-Green, S. (2005). Quest for the shaman: Shape-Shifters, Sorcerers and Spirit Healers in Ancient Europe [Busca pelo xamã: Metamorfos, feiticeiros e curandeiros espirituais na Europa Antiga]. Thames and Hudson
Berman, M. (2000). Wandering God: A study in nomadic spirituality [Deus que vagueia: Um estudo sobre a espiritualidade nômade]. State University of New York Press.

Bock, A. M. B., Teixeira, M. L. T., \& Furtado, O. (Orgs.) (2018). Psicologias: uma introdução ao estudo de Psicologia. Saraiva.

Castro, E. V. (2017). A inconstância da alma selvagem e outros ensaios de antropologia. Ubu.

Eliade, M. (1996). Yoga: Imortalidade e liberdade. Palas Athena.

Eliade, M. (2002). O xamanismo e as técnicas arcaicas do êxtase. Martins Fontes.

Fernandes, S. C. (2018). Xamanismo e neoxamanismo no circuito do consumo ritual das medicinas da floresta. Horizontes Antropológicos, 24(51), 289-314. https://doi.org/10.1590/ S0104-71832018000200011

Goleman, D., \& Davidson, R. J. (2017). A ciência da meditação: Como transformar o cérebro, a mente e o corpo. Objetiva.

Gøtzsche, P. (2016). Medicamentos mortais e crime organizado: Como a indústria farmacêutica corrompeu a assistência médica. Bookman. (Texto original publicado em 2013)

Grof, S. (1987). Além do Cérebro: nascimento, Morte e Transcendência em Psicoterapia. McGraw-Hill. (Texto original publicado em 1985)

Grof, S. (2010). Respiração holotrópica: Uma nova abordagem de autoexploração e terapia. Numina.

Grof, S. (2015). Cura profunda: A perspectiva holotrópica. Numina.

Grosfoguel, R. (2016). A estrutura do conhecimento nas universidades ocidentalizadas: racismo/sexismo epistêmico e os quatro genocídios/epistemicídios do longo século XVI. Sociedade e Estado, 31(1), 25-49. https:// doi.org/10.1590/S0102-69922016000100003

Hothersall, D. (2019). História da psicologia (4a. ed.). AMGH.

Jacó-Vilela, A. M., Ferreira, A. A. L., \& Portugal, F. T. (Orgs.). (2006). História da psicologia: rumos e percursos. Nau.

Jung, C. G. (2000). Arquétipos e o inconsciente coletivo. Vozes. (Texto original publicado em 1951).

Kopenawa, D., \& Albert, B. (2015). A queda do céu: Palavras de um xamã yanomami. Companhia das Letras. (Texto original publicado em 2013)

Krippner, S. (2007). Os primeiros curadores da humanidade: abordagens psicológicas e psiquiátricas sobre os xamãs e o xamanismo. Archives of Clinical Psychiatry (São Paulo), 34(Suppl. 1), 17-24. https://dx.doi.org/10.1590/S0101$\underline{60832007000700004}$ 
Lowen, A. (2017). Bioenergética. Summus. (Texto original publicado em 1994)

Malradi, E., \& Martins, L. B. (2016). A Psicologia diante dos saberes tradicionais: o caso do xamanismo. In Conselho Regional de Psicologia de São Paulo, Na Fronteira da Psicologia com os Saberes Tradicionais: Práticas e Técnicas (Vol. 2, pp. 67-

72). CRP - SP. http://www.crpsp.org.br/diverpsi/arquivos/ ColecaoDiverpsi_Vol2.pdf

Miller, M. J., Albarracin-Jordan J., Moore C., \& Capriles J. M. (2019). Chemical evidence for the use of multiple psychotropic plants in a 1,000-year-old ritual bundle from South America [Evidência química para o uso de múltiplas plantas psicotrópicas em um pacote ritual com mais de 1.000 anos da América do Sul]. Proceedings of the National Academy of Sciences of the United States of America. 2019;116(23):11207-11212. https://doi.org/10.1073/ pnas. 1902174116

Moebus, R. (2017). Práticas indígenas de produção do cuidado. Diversitates International Journal, 9(1), 27-45. http://www. diversitates.uff.br/index.php/1diversitates-uff1/article/ view/175/109

Pollan, M. (2018). Como mudar sua mente. O que a nova ciência das substâncias psicodélicas pode nos ensinar sobre consciência, morte, vícios, depressão e transcendência. Intrínseca.

Porto-Gonçalves, C. W., \& Quental, P. A. (2012). Colonialidade do poder e os desafios da integração regional na América Latina. Polis, 11(31), 295-332. http://dx.doi.org/10.4067/ S0718-65682012000100017

Quijano, A. (2005). Colonialidade do poder, eurocentrismo e América Latina. In E. Lander (Org.), A colonialidade do saber: eurocentrismo e ciências sociais (pp. 227-278). Clacso.

Rock, A. J., \& Krippner, S. (2011). Demystifying shamans and their world: A multi-disciplinary study [Desmistificando os xamãs e seu mundo: Um estudo multidisciplinar]. Imprint Academic.
Santos, B. S. (2008a). A gramática do tempo: para uma nova cultura política. Cortez.

Santos, B. S. (2008b). A filosofia à venda, a douta ignorância e a aposta de Pascal. Revista Crítica de Ciências Sociais, 80, 11-43. https://portalrevistas.ucb.br/index.php/RCEUCB/ article/view/1714

Schenberg, E. E. (2018). Psychedelic-Assisted Psychotherapy: A Paradigm Shift in Psychiatric Research and Development [Psicoterapia Psicodélico-Assistida: Uma Mudança Paradigmática na Pesquisa e Desenvolvimento Psiquiátrico]. Frontiers in pharmacology, 9, 733. https://doi. org/10.3389/fphar.2018.00733

Schultz, D. P., \& Schultz, S. E. (2002). História da Psicologia Moderna. Cultrix.

Singer, W., \& Ricard, M. (2018). Cérebro e Meditação: Diálogos entre o budismo e a neurociência. Alaúde.

Wilson, S. C., \& Barber, T. X. (1983). The fantasy-prone personality: Implications forunderstanding imagery, hypnosis, and parapsychological phenomena [A personalidade propensa à fantasia: Implicações para compreender imagens, hipnose e fenômenos parapsicológicos]. In A. A. Sheikh (Ed.), Imagery: Current theory, research, and application (pp. 340-390). Wiley.

Winkelman, M. J. (2002). Shamanic guidelines for psychedelic medicine [Diretrizes xamânicas para a medicina psicodélica]. In M. Winkelman, \& T. B. Roberts (Eds.), Psychedelic medicine. New evidence for hallucinogenic substances as treatments (pp. 143-167). Praeger.

Winkelman, M. J. (2010). Shamanism: A biopsychosocial paradigm of consciousness and healing [O xamanismo: Um paradigma biopsicossocial de consciência e cura]. Praeger. 